\title{
Novel thermocouples for automotive applications
}

\author{
Paul Gierth $^{1}$, Lars Rebenklau ${ }^{1}$, Klaus Augsburg ${ }^{2}$, Eric Bachmann ${ }^{2}$, and Lars Niedermeyer ${ }^{2}$ \\ ${ }^{1}$ Fraunhofer Institute IKTS, Winterbergstraße 28, 01277 Dresden, Germany \\ ${ }^{2}$ Technical University Ilmenau, Ehrenbergstraße 15, 98693 Ilmenau, Germany \\ Correspondence: Paul Gierth (paul.gierth@ikts.fraunhofer.de)
}

Received: 29 September 2017 - Revised: 29 November 2017 - Accepted: 5 December 2017 - Published: 2 February 2018

\begin{abstract}
Measurement of temperatures in engine and exhaust systems in automotive applications is necessary for thermal protection of the parts and optimizing of the combustion process. State-of-the-art temperature sensors are very limited in their response characteristic and installation space requirement. Miniaturized sensor concepts with a customizable geometry are needed. The basic idea of this novel sensor concept is to use thick-film technology on component surfaces. Different standardized and especially nonstandard material combinations of thermocouples have been produced for the validation of this technology concept. Application-oriented measurements took place in the exhaust system of a test vehicle and were compared to standard laboratory conditions.
\end{abstract}

\section{Motivation}

Downsizing of modern engines for automotive applications focuses on efficiency improvement and increasing emission standards. The correlating of performance increase with decreasing engine dimensions is often realized with turbo- or superchargers. The thermal management of the engine and exhaust systems gets more difficult when decreasing the component sizes. Many materials are used at their thermal limits. So miniaturized temperature sensors directly integrated on the surface of critical components are needed to control and optimize the combustion process and to protect the materials against overheating. State-of-the-art thermocouples or resistance thermometers (similar to PT100) could not be completely and firmly bonded to the components and are limited in their size because of the needed resistance area or housing for protection. Novel thick-film thermojunctions could be applied on these surfaces, so that it is possible to measure surface temperature fields without influencing the flow of the exhaust gas. The suitability of thick-film thermocouples for automotive applications has already been demonstrated (Rebenklau et al., 2015a, b). The main idea of the present work is to use the sensor directly on or in thermally stressed engine or exhaust parts. In that way the temperature signals will be generated not just near the areas of interest but also directly where they are needed to be measured. For the thick-film thermocouples, a measurement uncertainty of $\pm 5^{\circ} \mathrm{C}$ is targeted for this fundamental study. The possibility to protect thick-film thermocouples against harmful surroundings with only a couple of micrometres of overglaze is a good possibility to minimize thermal masses of the sensor and in that way help to improve sensor response times. The following experimental setup and results demonstrate the possibilities of the thick-film technology for such sensor applications, mainly based on planar substrates but a summary of the development process for tubular substrates is also given (diameter $>60 \mathrm{~mm}$ for exhaust systems).

\section{Sample preparation}

Thick-film thermocouples are designed and produced based on commercially available thick-film pastes. The resulting material combinations did not match the standard classification of thermocouples given in the DIN EN 60584 standard, because alloys such as $\mathrm{NiCr}$ are not fully commercially available as thick-film paste. Thus, mainly materials which are typically used for electronic screen-printed substrates will be tested as thermocouple materials. In that way, a high material availability is provided and a fast market introduction phase is guaranteed. The pastes are screen-printed with a 325-mesh screen on planar ceramic substrates $\left(\mathrm{Al}_{2} \mathrm{O}_{3}\right)$ for testing the material combinations and separately fired in a temperature range between $600-1400^{\circ} \mathrm{C}$ (Fig. 1a). This flat-sensor geometry is just used to validate the screen-printing process, insu- 


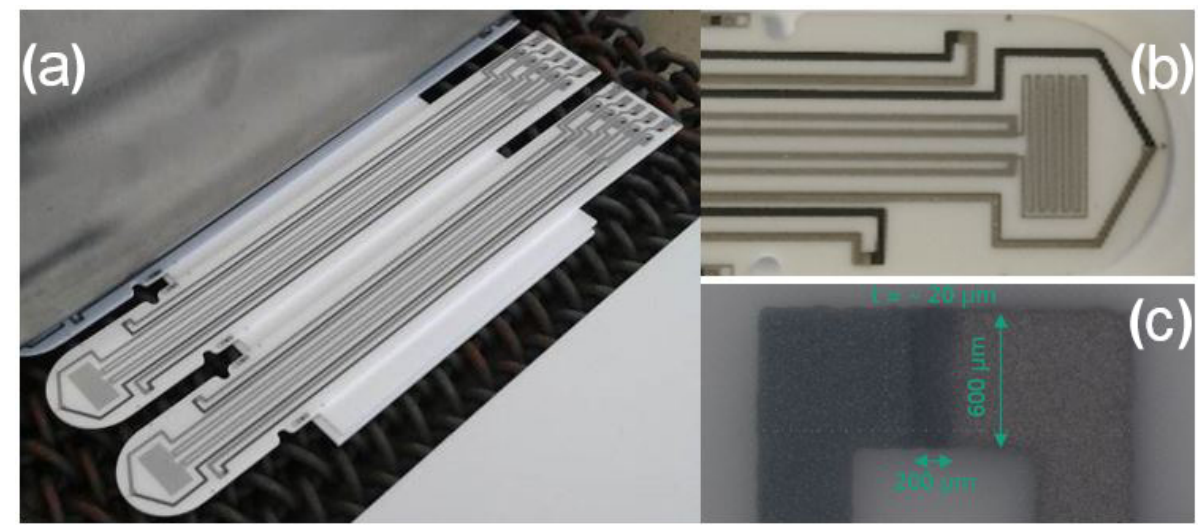

Figure 1. (a) Firing of thick-film thermocouples on alumina substrates, (b) sensor layout consisting of three thermocouples and one reference PT100 platinum resistance thermometer and (c) microscope images of the miniaturized thick-film thermojunction on a planar substrate.
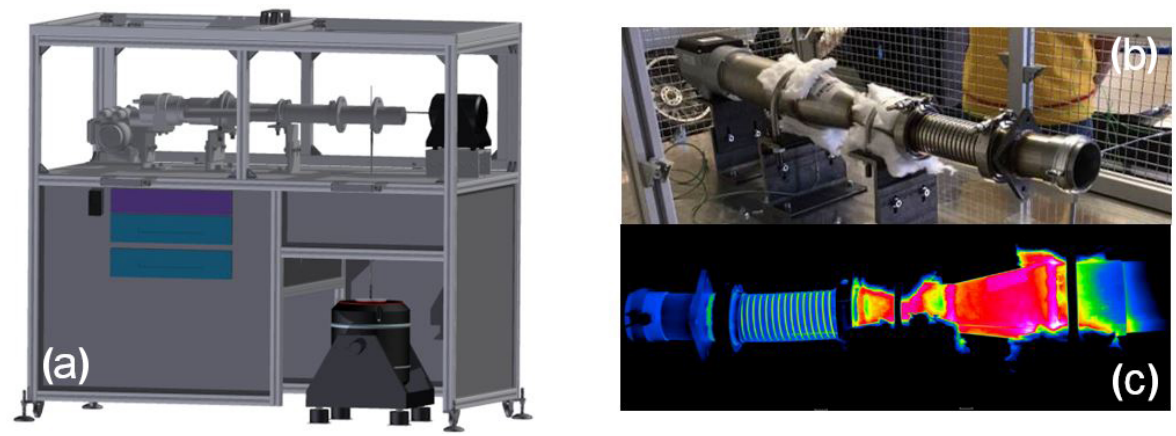

Figure 2. (a) Test rig layout consisting of several systems for heat generation and sensor stressing, (b) hot-air-exhaust test rig and (c) thermal image of the test rig.

lation materials and the metal paste combinations and will be further transferred to the surfaces of round and 3-D free-form objects.

Every produced thermojunction on these planar substrates has a length of $200 \mu \mathrm{m}$, a width of $600 \mu \mathrm{m}$ and a thickness of $20 \mu \mathrm{m}$ (overlapping area; Fig. 1c). The printing and firing sequence of the up to four different thick-film pastes on every substrate needs to take place in descending order of the firing temperature for every material. Platinum or palladium pastes with firing temperature over $1300^{\circ} \mathrm{C}$ were always processed first, followed by the interconnection metallization based on silver/palladium with $850^{\circ} \mathrm{C}$ processes last. The firing process takes place for temperatures greater than $900^{\circ} \mathrm{C}$ in a Carbolite HTF 1710 and below $900^{\circ} \mathrm{C}$ in a Centrotherm DO4800-125 firing furnace. To generate a standardized type $\mathrm{S}$ thermocouple, a $\mathrm{PtRh}_{10}$ thick-film paste has been developed at the Fraunhofer IKTS. Therefore, the needed metal powders, platinum (90 ma\%) and rhodium $(10 \mathrm{ma} \%)$, were homogenized and mixed with an ethyl cellulose polymer system. The viscosity of this mixture was adjusted with terpineol until it reaches a screen-printable level. Thick-film-paste manufacturers are also developing such a paste composition, but these products did not reach full market availability until recently.

\section{Experimental setup}

Fundamental material characteristics of thick-film thermojunctions were evaluated under laboratory and real-world conditions. Temperature differences over the thick-film thermojunctions were validated with platinum thick-film elements near the thermojunctions (hot end) and the interconnection area (cold end) on the validation substrates (Fig. 1a and $b$ ). The samples were interconnected by soldering or welding with extension wires in the interconnection area (cold end). The influence of the contact wires is negligible, referring to the thermal voltage, because both extension wires are made of the same material and in that way they generate an identical voltage on each side.

Samples were heated in laboratory conditions with temperature differences of up to $250 \mathrm{~K}$ in the temperature range of $50-300{ }^{\circ} \mathrm{C}$. The resulting thermal voltage and the resistances of the platinum resistor have been measured with a Keithley 2700 . A measurement uncertainty of $\pm 2{ }^{\circ} \mathrm{C}$ could be reached. Seebeck coefficients of the thermocouples, $S_{\mathrm{TC}}$, 


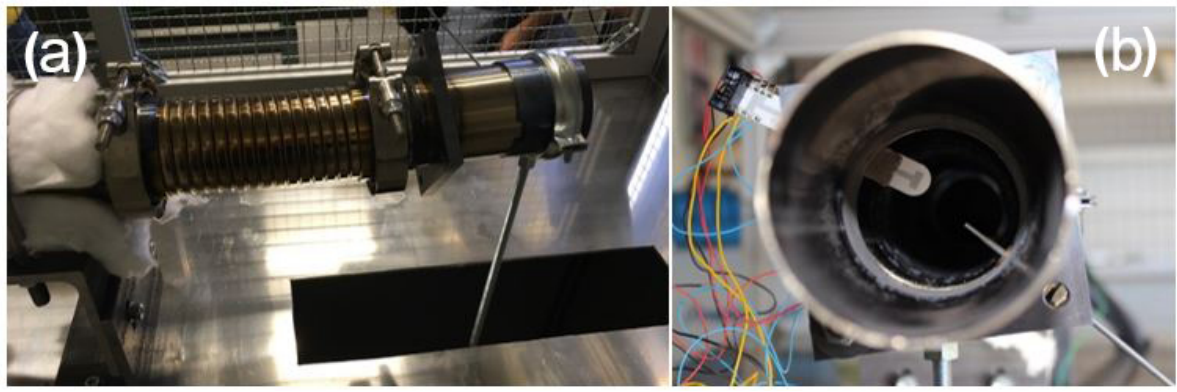

Figure 3. Assembly of characterization sensors in the test rig during long-term evaluation: (a) side view of the test rig and (b) end view inside the test rig with reference thermal sensor and thick-film validation sensor.
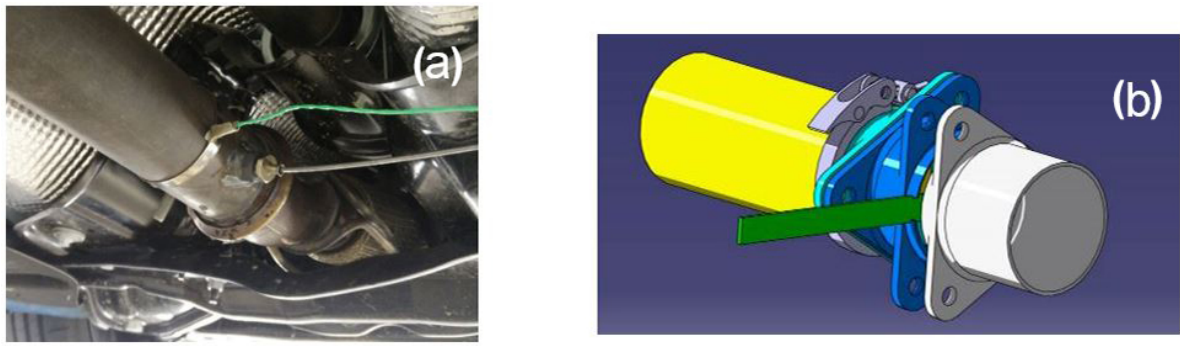

Figure 4. (a) Exhaust system of a Ford Focus RS Mk III with two mounted type K reference thermocouples and (b) mounting system for different thick-film thermocouple sensor layouts on planar and tubular substrates.

in correlation with the linear thermal voltage $U_{\text {th }}$ between the temperatures $T_{1}$ and $T_{2}$ have been calculated for every material combination according to Eq. (1):

$U_{\mathrm{th}}=\int_{T_{1}}^{T_{2}} S_{\mathrm{TC}} \mathrm{d} T$

Measurement under real-world conditions took place in a hot-air test rig at Technical University Ilmenau (Fig. 2). The test rig is exclusively build for testing the sensors under thermal and vibration stresses. It allows experimental studies of the sensor behaviours under reproducible conditions that are comparable to real-world conditions in the exhaust gas system of a car with a combustion engine. The test rig consists of a hot-air fan as heat source, isolated high-grade stainless steel tubes to transport the heat to the sensor, a regulator to control the temperature and a shaker system to stress the sensor.

Temperatures up to $900{ }^{\circ} \mathrm{C}$ combined with an air mass flow of $1000 \mathrm{~L} \mathrm{~min}^{-1}$ are reachable. Vibration stresses are realized with the help of a shaker system. In the radial direction, the sensor system is connected by a threaded rod with the shaker. This layout allows frequencies from 2 to $7000 \mathrm{~Hz}$ with a maximum acceleration of $20 \mathrm{~g}$ up to $2500 \mathrm{~g}$.

Long-term tests are important experiments for the market launch of any component, especially for temperature sensors used for security or protection applications. This study is focussing on such kinds of sensors and therefore expose them to the expected stress during the sensor lifetime. Basic functionality tests of the sensors took place at temperatures between 300 and $850^{\circ} \mathrm{C}$ combined with shaking frequencies between 17 and $433 \mathrm{~Hz}$ (amplitude 50-500 $\mu \mathrm{m}$; Fig. 3).

It can be seen that the validation substrates of the thickfilm thermocouples are much larger compared to the reference thermocouples. It needs to be emphasized that this sensor shape is only used for the fundamental material characterization under harsh conditions. Substrates which demonstrate an application of the final sensor shape are shown on Fig. 9. Besides the test bench, it is important to check the functionality and durability of the sensors under real-world conditions too. Thus, it is necessary to test the sensor in field conditions in a real exhaust gas system of a vehicle. High exhaust gas temperatures could be achieved in an engine with forced induction and a high displacement performance (test vehicle Ford Focus RS Mk III). The sensors were positioned in the exhaust system behind the turbocharger and the catalytic converter. This position is easily accessible (Fig. 4a) and shows possible temperatures up to $840^{\circ} \mathrm{C}$.

A mounting tool for installation of planar and tubular sensors in the exhaust gas system has also been developed (Fig. 4b). All sensor signals are recorded with the National Instruments CompactRIO measurement system with NI9213 modules. 
Table 1. Calculated Seebeck coefficients of different thick-film thermocouple combinations in the temperature range $50-300{ }^{\circ} \mathrm{C}$.

\begin{tabular}{llrr}
\hline Thick-film material combination & Firing & Seebeck coefficient in $\mu \mathrm{V} \mathrm{K}^{-1}$ & Coefficient of determination $R^{2}$ \\
\hline $\mathrm{Ag}-\mathrm{Ni}$ & sequential fired & 23.9 & 0.9956 \\
$\mathrm{Ag}-\mathrm{Pt}$ & sequential fired & 8.0 & 0.9799 \\
$\mathrm{Au}-\mathrm{Pt}$ & sequential fired & 10.7 & 0.9912 \\
$\mathrm{Pd}-\mathrm{Ag}$ & sequential fired & 6.6 & 0.9982 \\
$\mathrm{Cu}-\mathrm{Ni}$ & sequential fired & 15.9 & 0.9959 \\
$\mathrm{Pd}-\mathrm{Pt}$ & co-fired & 2.5 & 0.9976 \\
$\mathrm{Pd}-\mathrm{Pt}$ & sequential fired & 1.06 & 0.9687 \\
Pt-PtRh & co-fired & 4.79 & 0.9860 \\
Pt-PtRh & sequential fired & 4.82 & 0.9870 \\
\hline
\end{tabular}
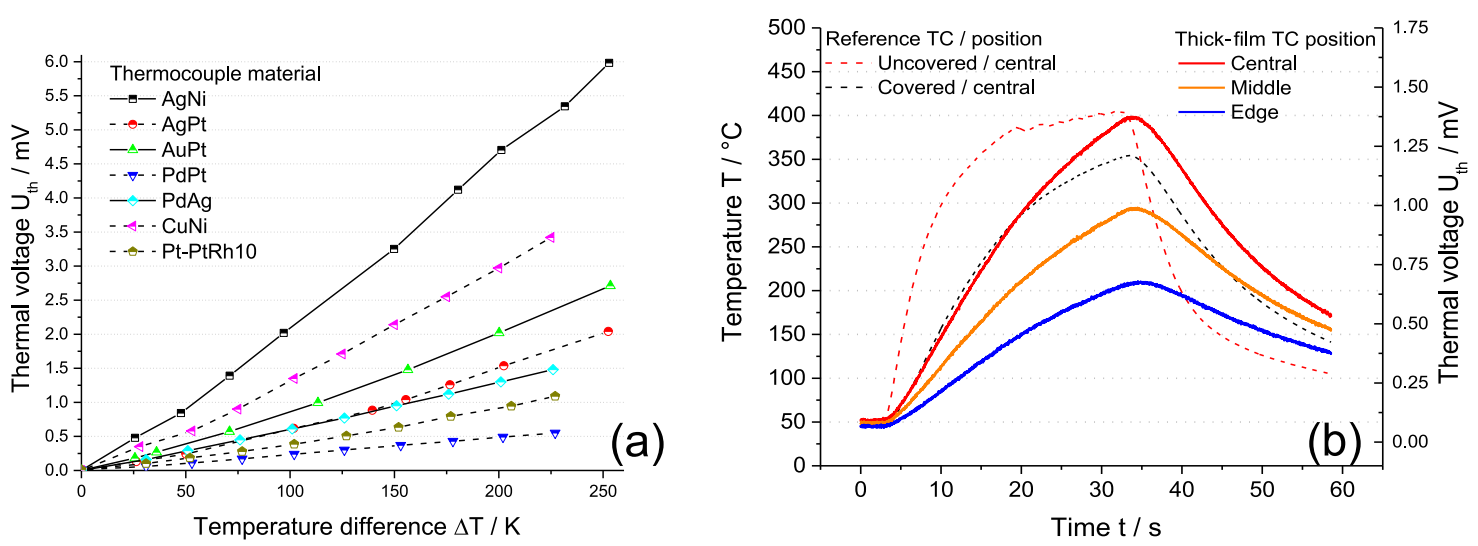

Figure 5. (a) Voltage in dependence of temperature difference and (b) comparison of standard thermocouples and thick-film thermocouples under real-world conditions. Pure wire thermocouples (uncovered) and housed thermocouples (covered) were used as reference thermocouples (positioned like central thermocouple). Thick-film thermocouples "TC" were positioned $20 \mathrm{~mm}$ (central), $10 \mathrm{~mm}$ (middle) and $5 \mathrm{~mm}$ (edge) from the pipe of the test rig.

\section{Results}

Measured voltages in dependence of temperature difference between hot and cold ends are summarized in Fig. 5a.

All sensor signals are nearly linear up to temperature differences of $200 \mathrm{~K}$. Thus, the Seebeck coefficient could be calculated according to Eq. (1) and is summarized in Table 1. The thick-film sensors were evaluated in the hot-air test rig in comparison to standard thermocouples. Exemplary results are shown in Fig. 5b. It can be seen that the thick-film thermocouples show good comparability under real-world conditions. A correlation between thermocouple position inside the gas flow (compare with sensor layout Fig. 1b) and the temperature field inside the pipe can clearly be seen and would be detectable more precisely with a thermocouple array.

Calculated results are comparable to literature values (DIN EN 60584-1; Irrgang and Michalowsky, 2003). Only Pt-Pd thermojunctions show much lower thermal voltages in comparison to literature values. A possible reason for this affect seems to be that the available Pd thick-film pastes show no completely comparable Seebeck coefficients to the bulk Pd material. Optical inspections of the material interconnection points are shown in Fig. 6. A diffusion effect of the materials during the high-temperature firing step can clearly be seen. Incompatible material combinations like $\mathrm{Ag}-\mathrm{Cu}$ can melt into each other, caused by the firing over the eutectic temperature of $779^{\circ} \mathrm{C}$. This leads to complete interruption (Fig. 6a). However, non-melting material combinations can also show local interruptions (Fig. 6b; Pt-PtRh 10 ). The reason for this is a material diffusion along the concentration gradient from the platinum-rich side to the platinum-deficient side. The diffusion gradient can be highly reduced by sequential firing of the materials. In that way, the sintering activity of the platinum-rich side could be reduced.

The long-term examinations of the sensors take place in the hot-air test rig. Examples of recorded sensor signals are shown in Fig. 7. Pt-PtRh 10 sensors show promising results in terms of durability and ageing (Fig. 7a). The platinum resistor temperature sensor on the ceramic substrate is used as reference. A correlation between thermojunction positions and locally measured temperatures, such as in Fig. 5b, can also be seen. The failure of middle sensors happened due to a crack in the sensor material, which was caused by the mechanical 


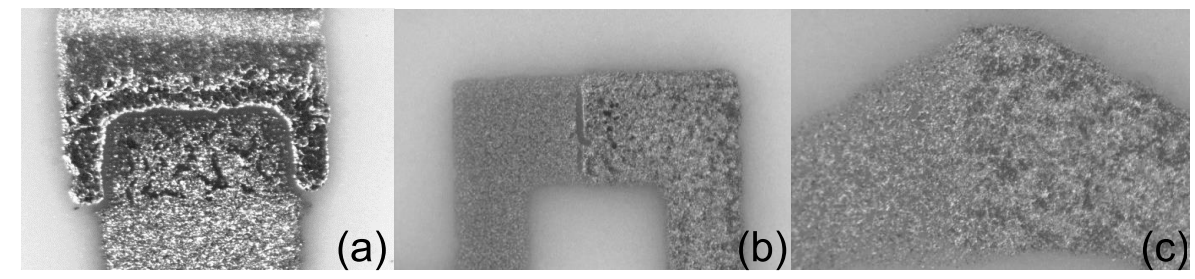

Figure 6. Material diffusion after firing: (a) Ag-Cu dissolution, (b) $\mathrm{Pt}-\mathrm{PtRh}_{10}$ diffusion caused by high sinter activity and (c) reduced $\mathrm{Pt}-\mathrm{PtRh} 10$ diffusion after sequential firing.
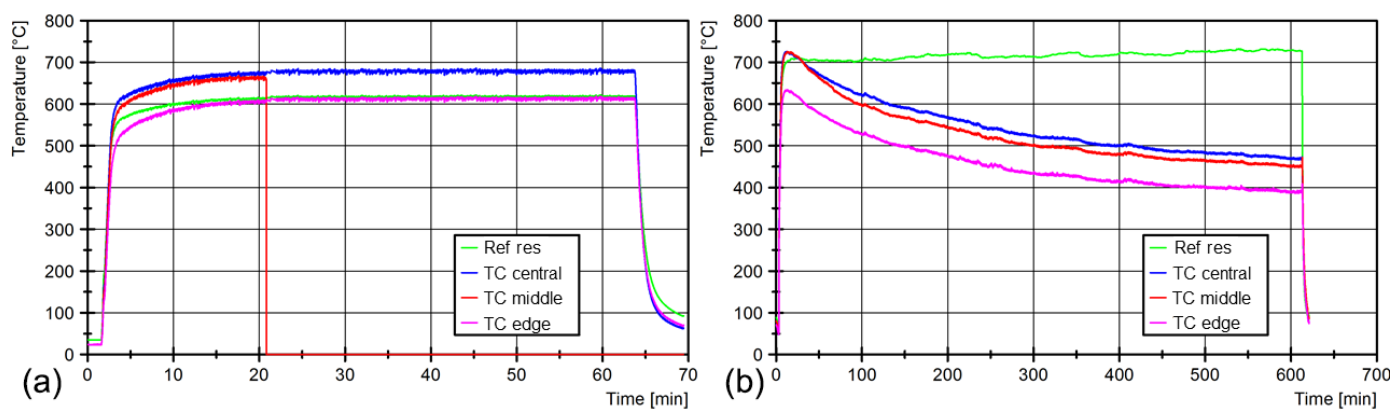

Figure 7. Long-term investigation of sensors in hot-air test rig at high temperature and mechanical stress caused by shaking (a) material combination $\mathrm{Pt}-\mathrm{PtRh} 10$ and (b) material combination $\mathrm{Ag}-\mathrm{Pd}$.

stress during shaking. Results like this were used to further improve sensor geometries in case of linear sensor designs. Other material combinations like Ag-Pd show unacceptable long-term stabilities at high temperatures (Fig. 7b). The decreasing of the sensor signal was caused by a silver diffusion inside the palladium, because both materials can completely dissolute in each other. In that way, an intermetallic area is formed between the materials. The exact dimension, Seebeck coefficient and temperature difference of this area are unknown but influence the output voltage of the complete thermojunction. Therefore, a correct calculation of the temperature based on the resulting voltage is not possible.

Currently, all promising material combinations are under investigation for real-world conditions on ceramic substrates. For the real-world test conditions, screen-printing on high-temperature, stable and metallic substrates is necessary. Therefore, an insulation layer between the substrate and the electrical sensor elements is necessary. Such screen-printable glass insulation layers were investigated on different kinds of steel substrates. Steel grades that are of interest are 1.4828, XSiMo5-1 and NiSiCr35,5. Only glass compositions with an acceptable adhesion to the substrates were further investigated in terms of insulation resistance. Figure 8a shows the insulation resistance of a commercially available glass composition on one type of steel for up to $400^{\circ} \mathrm{C}$.

The insulation resistance decreases with increasing temperature. This is caused by increasing ionic conductivity. Such a drastically decrease would also reduce the sensor signal quality especially at high temperature. Therefore, the
Fraunhofer IKTS developed a novel insulating glass composition, which shows a much higher temperature stability with the industrially relevant steel 1.4828 (Fig. 8b). The material compatibility of this developed insulation, with standard thick-film pastes and long-time stability of the insulating resistance (especially at high temperatures), is currently under investigation.

The previous work focussed on the basic material characterization of thick-film thermocouples. Next, the transfer from planar to tubular substrates takes place. Therefore, a special screen-printing test rig has been produced at the IKTS. With this system, tubular ceramic and metallic substrates up to diameters of $70 \mathrm{~mm}$ can be surface screenprinted. A diameter of $70 \mathrm{~mm}$ is correlates to typical diameters of exhaust gas systems. The aim is to develop a miniaturized temperature sensor network for the detection of complete temperature fields on component surfaces. Therefore, the characterization layout shown in Fig. 9a has been developed. This layout consists of 30 individual thermocouples in different positions and different miniaturization sizes. The complete surface temperature field of the component can be measured by individual evaluation of the 30 sensor signals. The tubular component shape is only used to demonstrate the 3-D integration of the sensor array. The transfer on completely free-form surfaces is currently under investigation. To analyse the thermojunction array on the component surface, it is necessary to contact each thick film with extension wires made out of corresponding material. Thus, a constant wellknown reference temperature can be used by the extension 

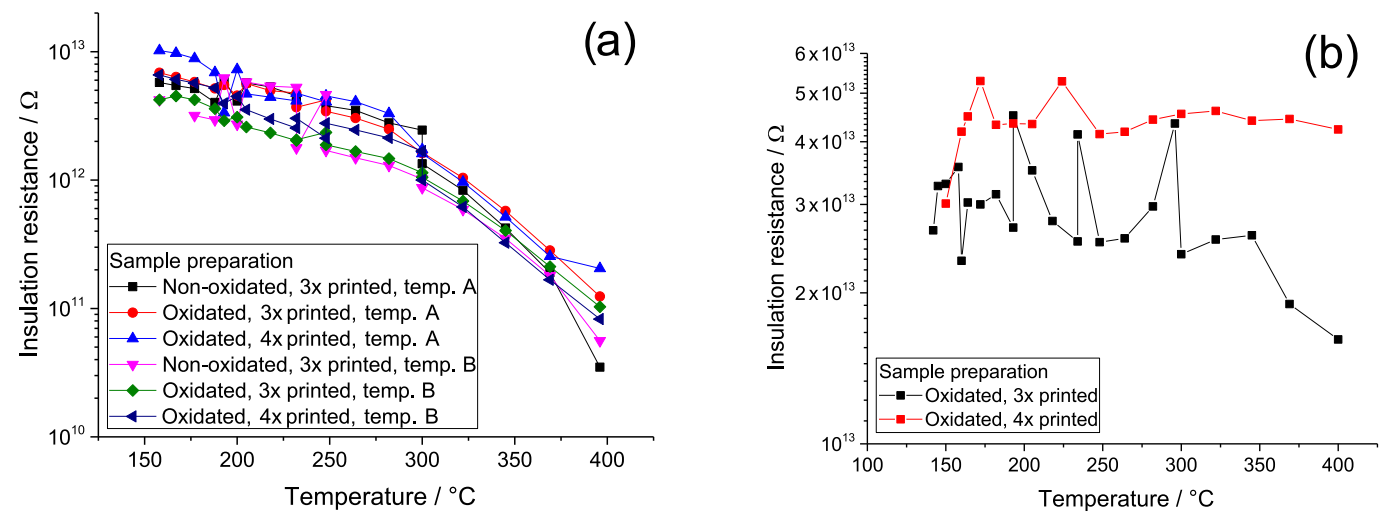

Figure 8. (a) Insulation resistance of glass insulation of steel substrate and (b) insulation resistance of IKTS glass composition on steel 1.4828 .
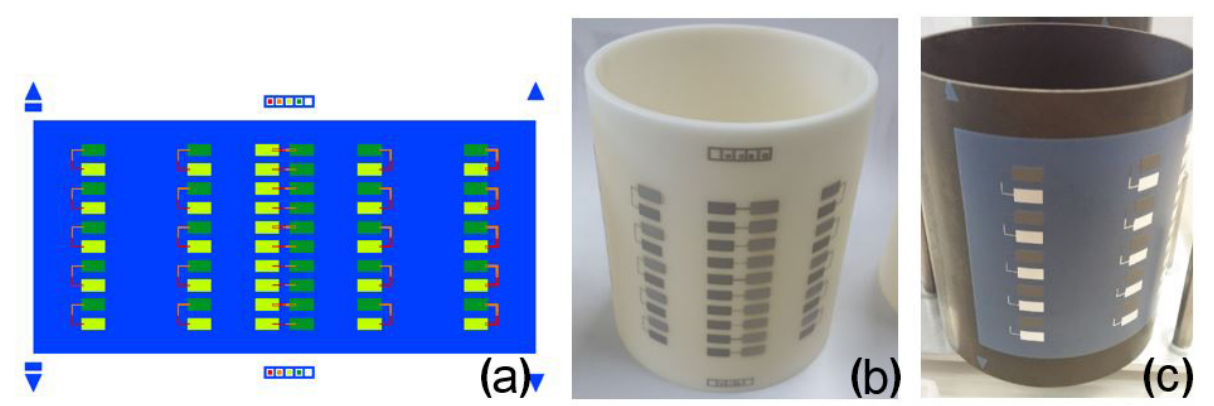

Figure 9. Tubular screen-printing: (a) screen-printing layout consisting of up to 30 thermocouples on a tubular surface, (b) screen-printing on an aluminium oxide substrate and (c) screen-printing of glass insulation paste on steel 1.4828 .

wire interconnection to connect to two temperature measurement cards from National Instruments with 16 channels each. The characterization and long-time evaluation will be presented in further works.

\section{Conclusions}

Engine and exhaust-gas-system components are exposed to steadily increasing temperatures. State-of-the-art temperature sensors can not always be used because of the ongoing miniaturization of components. Therefore, novel sensor concepts based on thick-film sensor networks for temperature field detection on the surface and inside of these automotive parts have been developed. The presented paper focuses on the basic characterization of thick-film materials under laboratory and real-world conditions. Promising material combinations for different temperature ranges have been developed. The possibility to transfer these materials, even on electrically conductive surfaces like steel exhaust parts, could be demonstrated. The results are very promising and the transfer to three-dimensional surfaces currently takes place.
Data availability. Underlying research data can be requested by contacting the authors. All measurement data were generated by the authors, no third party results were used.

Competing interests. The authors declare that they have no conflict of interest.

Special issue statement. This article is part of the special issue "Sensor/IRS2 2017". It is a result of the AMA Conferences, Nuremberg, Germany, 30 May-1 June 2017.

Acknowledgements. This work was funded by the German Ministry of Education and Research through the Association of German Engineers and the Association for Electrical, Electronic and Information Technologies (project FreeSense-HT, 03VP00112), which is gratefully acknowledged.

Edited by: Jörg Hollandt

Reviewed by: two anonymous referees 


\section{References}

DIN EN 60584-1: Thermocouples - Part 1, Beuth Verlag, 2013.

Irrgang, K. and Michalowsky, L.: Temperaturmesspraxis mit Widerstandsthermometern und Thermoelementen, VulkanVerlag GmbH, Essen, Germany, ISBN 978-3802722004, 2003.

Rebenklau, L., Gierth, P., Paproth, A., Irrgang, K., Lippmann, L., Wodtke, A., Niedermeyer, L., Augsburg, K., and Bechtold, F.: Temperature sensors based on thermoelectric effect, 2015 European Microelectronics Packaging Conference (EMPC), Friedrichshafen, 1-5, ISBN 978-0-9568086-2-2, 2015a.
Rebenklau, L., Gierth, P., Irrgang, K., Lippmann, L., Wodtke, A., Niedermeyer, L., Augsburg, K., and Bechtold, F.: Novel thermoelectric temperature sensors, 11th IMAPS/ACerS CICMT, 230 233, https://doi.org/10.4071/CICMT-WP14, 2015 b. 